\title{
Phytochemical Analysis of Pergularia Daemia for Its Bioactive Components through Gas Chromatographic Mass Spectrometry (GCMS)
}

\author{
${ }^{1,}$ Sridevi G , ${ }^{2,}$ Prema Sembulingam , ${ }^{3,}$ Sekar Suresh , ${ }^{4,}$ Sembulingam K \\ I, Senior Lecturer, Department of Physiology, Sathyabama University Dental College and Hospital, Jeppiar \\ Nagar, Rajiv Gandhi road (Old Mahabalipuram road), Chennai - 600119 \\ 2, Professor, Department of Physiology, Madha Medical college \& Research Institute, Kuntrathur main Road, \\ Kovur, Thandalam near Porur, Chennai- 600112 \\ ${ }^{3,}$ Reader, Department of Anatomy, Sathyabama University Dental College and Hospital, Jeppiar Nagar, Rajiv \\ Gandhi road (Old Mahabalipuram road), Chennai - 600119 \\ 4, Professor, Department of Physiology, Madha Medical college \& Research Institute, Kuntrathur main Road, \\ Kovur, Thandalam near Porur, Chennai- 600112
}

\begin{abstract}
Pergularia daemia is a hispid perennial herb that grows along the roadsides of India and other tropical and subtropical regions. This medicinal plant is traditionally used to treat various ailments like infantile diarrhea, malarial fever, vatha, convulsion, asthma, poisoning, mental disorder, anemia, leprosy, piles etc. However, the bioactive components of this plant are not yet established fully. In the present study, the ethanol extract of this plant was subjected for phytochemical qualitative analysis through Gas Chromatographic Mass Spectrometry (GCMS) and the bioactive components were identified. The analysis revealed the presence of flavonoid, tannins, alkaloid, glycosides, terpenoids, steroids and carbohydrates. Five bioactive constituents were identified namely 2-hydroxy- methyl ester with retention time 6.607, 2-Methoxy-4-vinylphenol with retention time 8.215, Phthalic acid di-(1-hexen-5-yl) ester with retention time 12.279, l-(+)-Ascorbic acid 2,6dihexadecanoate with retention time 16.751 and Methyl (Z)-5,11,14,17-eicosatetraenoate with retention time 18.556. The presence of these bioactive constituents in the plant extract may authenticate the scientific evidences for various pharmacological activities and therapeutic potentiality of the plant.
\end{abstract}

KEY WORDS: Pergularia Daemia, Herbal Medicine, Holistic Treatment, Bioactive Components, Gas Chromatographic Mass Spectrometry

\section{INTRODUCTION}

Healing through herbal medicine is the most ancient form of treatment known to mankind. The age-old holistic medical systems such as Ayurveda, siddha, homoeopathy etc., are in practice of using the herbal plant drugs or formulations to treat various ailments. According to World Health Organization (WHO), more than $80 \%$ of the world's population in poor and underdeveloped countries depend on traditional plant-based medicines for their primary healthcare needs [1]. Its efficacy, safety, almost- nil adverse effects and lesser costfactor have attracted the attention of developed and economically sound countries also. For the same reasons, even the leading pharmaceutical companies started entering into the field of medicinal plant research. Pergularia daemia ( $P$ daemia) is one such plant, popularly known as "Veliparuthi" in Tamil and "Utranajutuka" in Hindi. It is a hispid perennial herb that grows along the roadsides of India and other tropical and subtropical regions. Earlier reports indicate various beneficial uses of the herb, validating it as a medicinal herb. Traditionally the whole plant is used as anthelmintic, antipyretic, laxative and expectorant and to treat infantile diarrhea and malarial fever. The root of the plant is effective in treating convulsions, asthma, poisoning, mental disorder, anemia, leprosy and piles (2). Dried leaf of this plant is used as an emetic agent and is effective in treating bronchitis [3], asthma [4], rheumatic fever [5], amenorrhea, dysmenorrhea [6,7] and wounds [8] and to facilitate parturition. Fresh roots and shoots are found to be useful in treating whooping cough [9]. The shoots of the plant are considered to be an effective agent for abortion (10]. Stem bark is used in treating malaria [11] and twig is effective as an antipyretic agent and serves as a good appetizer [12]. All these therapeutic potentiality of Pdaemia may be attributed to the presence of its phytochemical constituents which is not yet explored thoroughly. In the present study the ethanol extract of the aerial parts of the plant was subjected for phytochemical analysis followed by quantitative determination of organic compounds by Gas Chromatogram mass spectrometric method (GCMS). 
Perusal of literature reveals the presence of certain bioactive substances in $P$ daemia such as glucoside, terpenoids, sterols, $\alpha$-amyrin, $\alpha$-amyrin acetate, $\beta$-amyrin, $\beta$-sitosterol, lupeol acetate, hentriacontane, betaine and different polypeptides (13). Fresh shoots and flowers were shown to contain hyperoside (flavonol), flavonoids and saponins (14). Inorganic substances like potassium chloride $(\mathrm{KCl})$ and potassium nitrate $(\mathrm{KNO} 3)$ were found in the whole plant (14). Recent studies have shown the presence of a bitter resin, two bitter principles and a glucoside. Two new sterols namely $5 \beta$-stigmast-7-(8)-en-3-3a-ol and $5 \beta$ - stigmast-8(14)-en-3aol were also been isolated from the plant. Numerous cardenolides were also found in the stalks. Rastogi RP and Mehrotra BN found alkaloid, daemine, uzarogenin, and coroglaucigenin in the leaves and roots and calotropin, calactin, corotoxigenin, calotoxin, calotropagenin, uscharin, dihydrocalotropagenin, uacharidin and protouscharin, in the seeds (15). In spite of the identification of these components in $P$ daemia, the therapeutic uses of various parts of this plant raised the curiosity regarding the existence of a lacuna in the area of the presence of some more bioactive substances in this plant. Hence this venture is taken up.

\section{1. Collection of the plant:}

\section{MATERIALS AND METHODS}

The whole plant was collected from Karuppur, Salem district, Tamil Nadu in India, and the voucher specimen was deposited in the Herbarium and authenticated in CAS Botany Department, University of Madras (Authentication No. MUCASB-H106)

\section{2. Preparation of extract:}

The aerial part consisting of the leaves, stem and flowers was separated from the whole plant and was washed in water to remove the dust and the sand. Then it was dried in shade at room temperature and was powdered in an electric blender. This powder was subsequently sieved to obtain a fine powder. Then, the ethanol extract of the fine powder was prepared by treating it successively with $95 \%$ ethanol in a soxhlet apparatus by continuous heat exposure for 72 hours. The extract was concentrated in rotary vacuum evaporator at $40^{\circ} \mathrm{C}$ and reconstituted in minimum amount of dimethyl sulphoxide (DMSO) and dried extract was stored in refrigerator at $4^{\circ} \mathrm{C}$ for their future use in phytochemical analysis.

\section{3. Phytochemical analysis}

Ethanol extract of the plant was tested for the presence of various bioactive compounds.

Test for flavonoid: To $1 \mathrm{ml}$ of the extract, few drops of $1 \% \mathrm{NH}_{3}$ was added in a test tube. An intense yellow colour was produced indicating the presence of flavonoid compounds.

Test for tannins: To $1 \mathrm{ml}$ of extract, $2 \mathrm{ml}$ of $5 \% \mathrm{FeCl}_{3}$ was added. Formation of blue black precipitate indicated the presence of tannins.

Test for alkaloids: $1 \mathrm{ml}$ of the extract was stirred with $2 \mathrm{ml}$ of $2 \mathrm{~N}$ hydrochloric acid and Mayer's reagent (Potassium mercuric iodide solution) was added to it. A white turbid precipitate was formed showing the presence of alkaloids.

Test for glycosides: To $1 \mathrm{ml}$ of extract, $1 \mathrm{ml}$ concentrated sulphuric acid $\left(\mathrm{H}_{2} \mathrm{SO}_{4}\right)$ was added. After hydrolysis of test solution, Fehling's solution was added. A black red precipitate was formed indicating the presence of glycosides.

Test for terpenoids: $2 \mathrm{ml}$ of extract was dissolved in $2 \mathrm{ml}$ of chloroform and evaporated to dryness. $2 \mathrm{ml}$ of concentrated $\mathrm{H}_{2} \mathrm{SO}_{4}$ was carefully added to the mixture to form a layer. An interface with reddish brown coloration was formed indicating the presence of terpenoids.

Test for steroids: $2 \mathrm{ml}$ of extract was dissolved in $2 \mathrm{ml}$ of chloroform and $2 \mathrm{ml}$ of concentrated $\mathrm{H}_{2} \mathrm{SO}_{4}$ was added along the sides of the test tube. The upper layer turned red and $\mathrm{H}_{2} \mathrm{SO}_{4}$ layer showed yellow colour with green fluorescence indicating the presence of steroids.

Test for carbohydrates: To $1 \mathrm{ml}$ of extract, $5 \mathrm{ml}$ of Benedict's reagent was added and boiled for 5 minutes. Formation of bluish green colour showed the presence of carbohydrates. When this was boiled for few minute more, a reddish pink colour was formed indicating the presence of flavonoid. 
Table 1. Phytochemical components in the ethanol extract of aerial parts of $P$ daemia

\begin{tabular}{|c|c|c|}
\hline S No & $\begin{array}{c}\text { Phytochemical } \\
\text { Components }\end{array}$ & $\begin{array}{c}\text { Ethanol extract } \\
\text { of } P \text { daemia }\end{array}$ \\
\hline 1 & Flavonoid & Present \\
\hline 2 & Tannins & Present \\
\hline 3 & Alkaloid & Present \\
\hline 4 & Glycosides & Present \\
\hline 5 & Terpenoids & Present \\
\hline 6. & Steroids & Present \\
\hline 7. & Carbohydrates & Present \\
\hline
\end{tabular}

\section{Gas Chromatography Mass Spectrometry (GCMS) analysis}

GCMS analysis is a common confirmation test. It separates all the components in a sample and provides a representative spectral output. The sample is injected into the injection port of the Gas Chromatography (GC) device. The GC instrument vaporizes the sample and then separates and analyzes the various components. Each component ideally produces a specific spectral peak that may be recorded on a paper chart electronically. The time elapsed between injection and elution is called the "retention time." The retention time can help to differentiate between some compounds. The peak is measured from the baseline to the tip of the peak.

\section{Identification of Bioactive Constituents by GCMS}

GC analysis of the ethanol extract of aerial parts of the plant was performed using a Shimadzu GC 17A - QP5050A gas chromatograph. The oven temperature was programmed to be $290.00^{\circ} \mathrm{C}$ at a rate of $10^{\circ} \mathrm{C} / \mathrm{min}$; the carrier gas was helium with a flow rate of $1 \mathrm{ml} / \mathrm{min}$. The sample was injected using the split sampling technique in the ratio of $1: 10$. Retention indices (RI) of the compounds were determined by comparing to the retention times of a series and identification of each component was confirmed by comparison of its retention index either with those of authentic compounds or with data in the literature. Interpretation of Mass-Spectrum was carried out by using the database of National institute Standard and Technology (NIST) having more than 62,000 patterns. The spectrum of the unknown components was compared with the spectrum of known components stored in the NIST library. The name, molecular formula, molecular weight and chemical structure of the components of the test materials were ascertained. The peak in GCMS of ethanol extract of $P$ daemia showed the presence of the secondary phytochemical compounds like phenolic and fatty acids and its esters. (Fig.1, Fig 2, Fig 3, Fig 4, Fig 5, Fig 6)

\section{RESULTS AND DISCUSSION}

The phytochemical characteristics of the $P$ daemia extract are summarized in Table 1 . The ethanol extract from the aerial parts of this plant contains flavonoid, tannins, alkaloids, glycosides, terbenoids, steroids and carbohydrates. By GCMS method, benzoic acid compound, phenolic compound, organic acid ester, fatty acid and fatty acid ester were isolated by their retention time (Table 2, Fig 1). Mass spectrum of the bioactive compounds with their retention time (RT) is shown in the Figures 2.3.4.5 and 6. GCMS is one of the hyphenated analytical techniques that help to do qualitative and quantitative evaluation of the chemical components in a sample. It involves two different techniques in a single method. It works on the principle of gas chromatography (GS) and mass spectrometry (MS). By GS, the components of a mixture are separated depending on their volatility (ease with which they evaporate into gas) and by MS individual characterization of the components are done depending on their structure. GCMS is also useful in many fields like detection of

Table 1. Bioactive compounds in $P$ daemia identified by Gas Chromatography Mass Spectrometry (GCMS)

\begin{tabular}{|c|c|c|c|c|c|c|}
\hline S no & $\mathrm{RT}(\min )$ & $\begin{array}{l}\text { Name of the } \\
\text { compound }\end{array}$ & $\begin{array}{c}\text { Compound } \\
\text { nature }\end{array}$ & $\begin{array}{c}\text { Molecular } \\
\text { formula }\end{array}$ & $\begin{array}{c}\text { Molecular } \\
\text { weight }\end{array}$ & Therapeutic use \\
\hline 1 & 6.607 & $\begin{array}{l}\text { Benzoic acid, 2-hydroxy-, } \\
\text { methyl ester }\end{array}$ & $\begin{array}{l}\text { Benzoic acid } \\
\text { compound }\end{array}$ & $\mathrm{C} 8 \mathrm{H} 8 \mathrm{O} 3$ & 152 & Antimicrobial \\
\hline 2 & 8.215 & 2-Methoxy-4-vinylphenol & $\begin{array}{l}\text { Phenolic } \\
\text { compound }\end{array}$ & $\mathrm{C} 9 \mathrm{H} 10 \mathrm{O} 2$ & 150 & $\begin{array}{c}\text { Anti-microbial, Analgesic } \\
\text { Anti-oxidant, } \\
\text { Anti-inflammatory }\end{array}$ \\
\hline 3 & 12.30 & $\begin{array}{l}\text { Phthalic acid, di-(1- } \\
\text { hexen-5-yl) ester }\end{array}$ & $\begin{array}{l}\text { Organic acid } \\
\text { ester }\end{array}$ & $\mathrm{C} 20 \mathrm{H} 26 \mathrm{O} 4$ & 330 & Antifungal. \\
\hline 4 & 16.751 & $\begin{array}{l}\text { 1-(+)-Ascorbic acid 2,6- } \\
\text { dihexadecanoate }\end{array}$ & Fatty acid & C38H68O8 & 652 & $\begin{array}{c}\text { Anti-oxidant, anti-inflammatory, } \\
\text { anti- nociceptive, anti-bacterial, } \\
\text { enhances sperm motility }\end{array}$ \\
\hline 5 & 18.556 & $\begin{array}{l}\text { Methyl (Z)-5,11,14,17- } \\
\text { eicosatetraenoate }\end{array}$ & Fatty acid ester & $\mathrm{C} 21 \mathrm{H} 34 \mathrm{O} 2$ & 318 & $\begin{array}{l}\text { Anti-bacterial, to treat dysentery } \\
\text { and diarrhea }\end{array}$ \\
\hline
\end{tabular}


Fig.1. Identification of Bioactive Constituents by GCMS

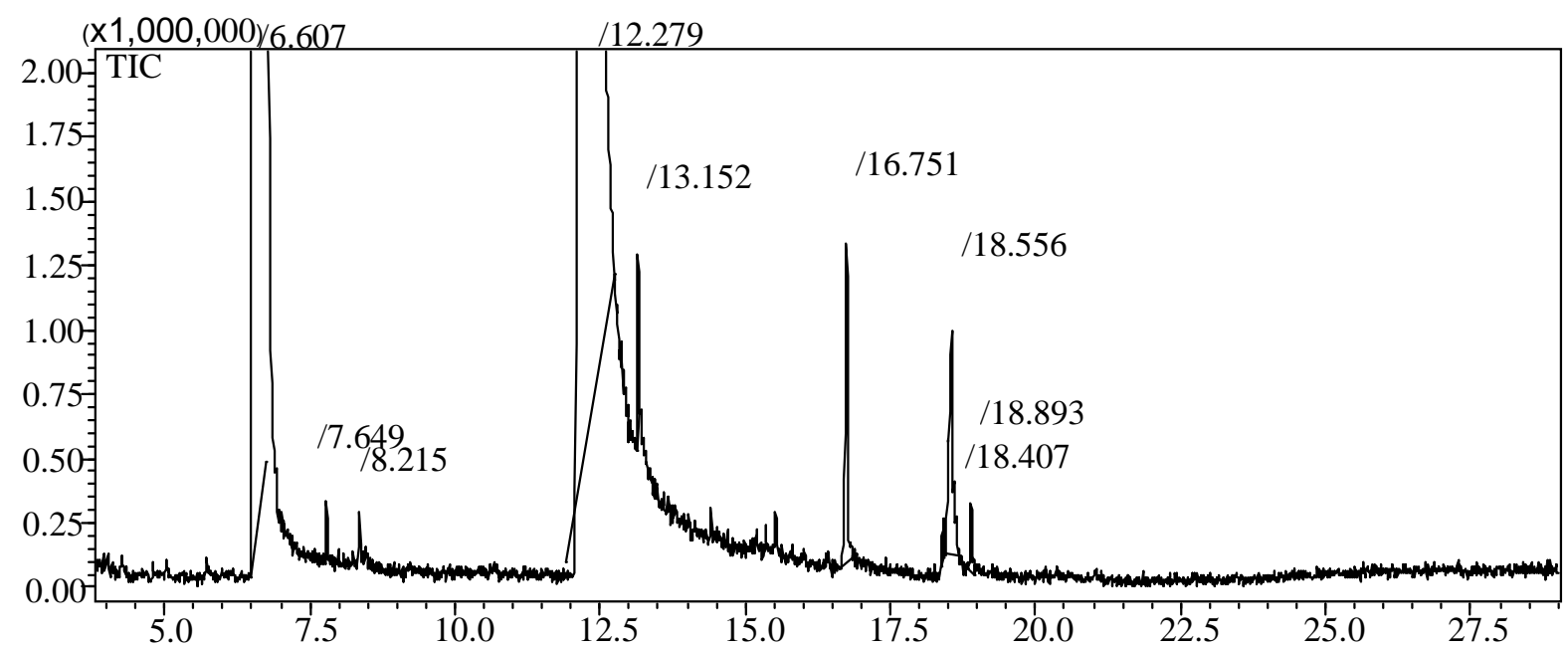

environmental pollution, in criminal forensics, in law enforcement, in sports for detecting doping, in explosive detection, food analysis, astrochemistry and in medical field $[16,17]$

The results of the present study by GCMS confirm the presence of bioactive components which may be responsible for their medicinal values and physiological activities [18]. The phytochemicals like tannins, alkaloid, terpenoids, steroids and saponins were already shown to be therapeutically effective. Mukeshwar et al stated that alkaloids in plants are used as anesthetic agents in medicine [19]. Saponins in some Chinese and Japanese medical herbs were reported to be effective as tonic and stimulating agents [20]. The presence of some of these compounds has also been confirmed to have antimicrobial activity [21].

Fig 2. Mass spectrum of Benzoic acid, 2-hydroxy-, ethyl ester (RT:6.607)

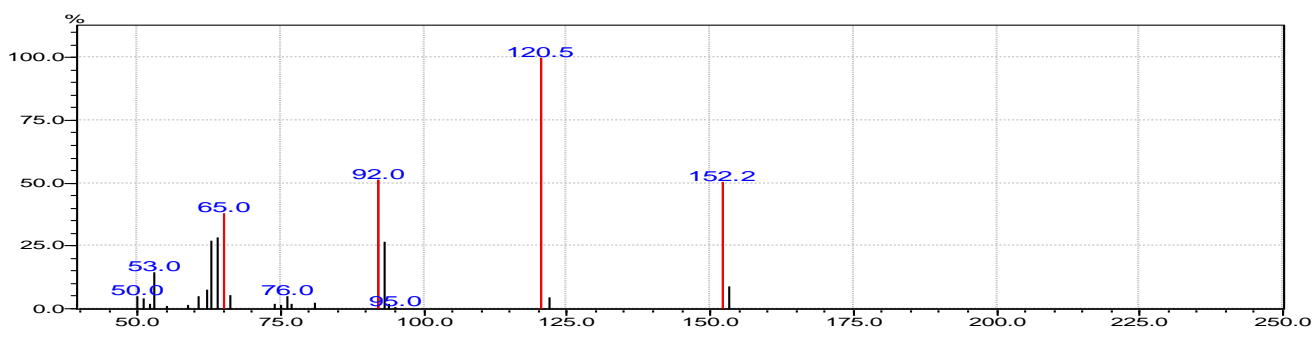

Hit\#:1 Entry:22339 Library:NIST05.LIB

SI:78 Formula:C9H10O3 CAS:118-61-6 MolWeight:166 RetIndex:1380

Compound name: Benzoic acid, 2-hydroxy-, ethyl ester \$ Salicylic acid, ethyl ester \$\$ Ethyl ohydroxybenzoate \$ Ethyl salicylate \$\$

Fig 3. Mass spectrum of 2-Methoxy-4-vinylphenol (RT:8.215)

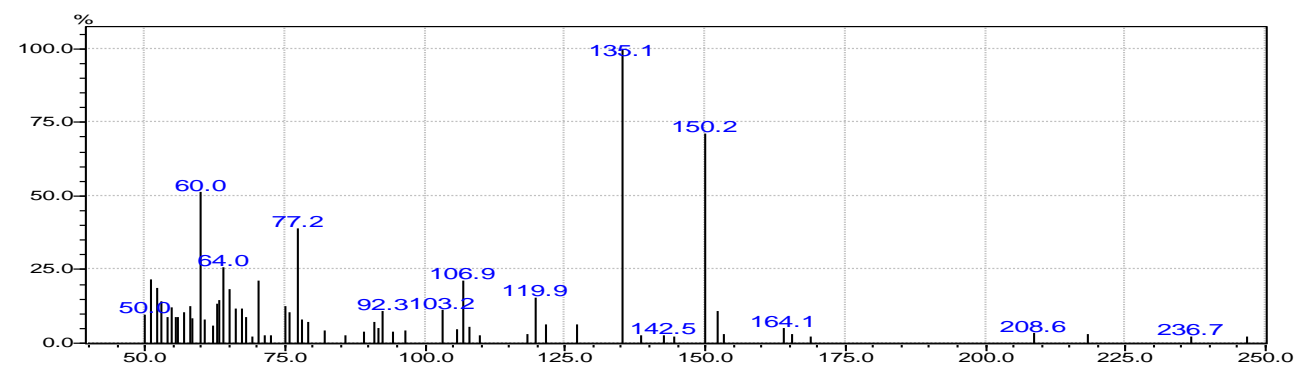

Hit\#:1 Entry:14775 Library:NIST05.LIB

SI:74 Formula:C9H10O2 CAS:7786-61-0 MolWeight:150 RetIndex:1293

Compound Name:2-Methoxy-4-vinylphenol \$ Phenol, 4-ethenyl-2-methoxy- \$\$ Phenol, 2-methoxy-4-vinyl-phenol. 
Fig 4. Mass spectrum of Phthalic acid, di-(1-hexen-5-yl) ester (RT:12.30)

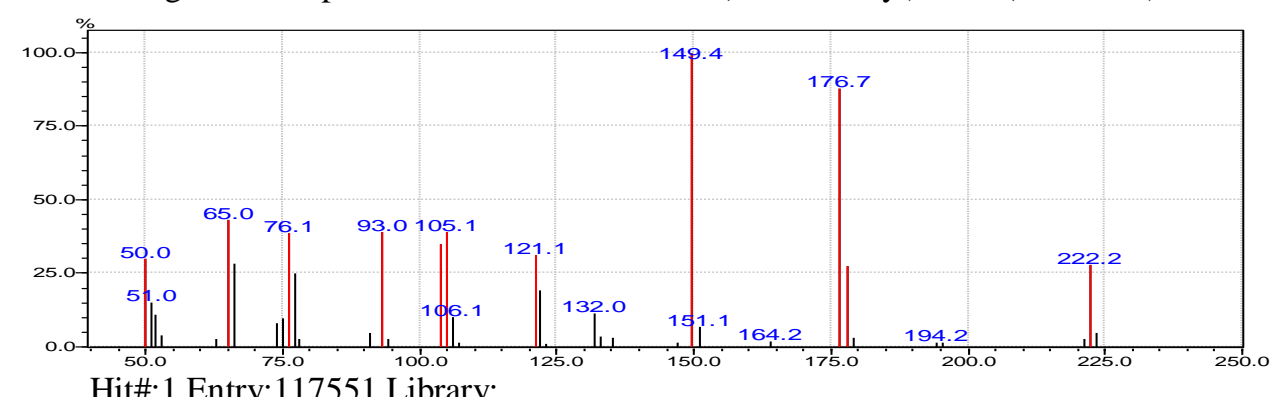

Hit\#:1 Entry:117551 Library:

SI:? Formula:C20H26O4 CAS:0-0-0 MolWeight:330 RetIndex:2286

Compound Name: Phthalic acid, di-(1-hexen-5-yl) ester

Hence it could be inferred that the plant extracts could be a source for the industrial manufacture of drugs useful in the chemotherapy of some microbial infection.

Fig 5. Mass spectrum of 1-(+)-Ascorbic acid 2,6-dihexadecanoate (RT:16.75)

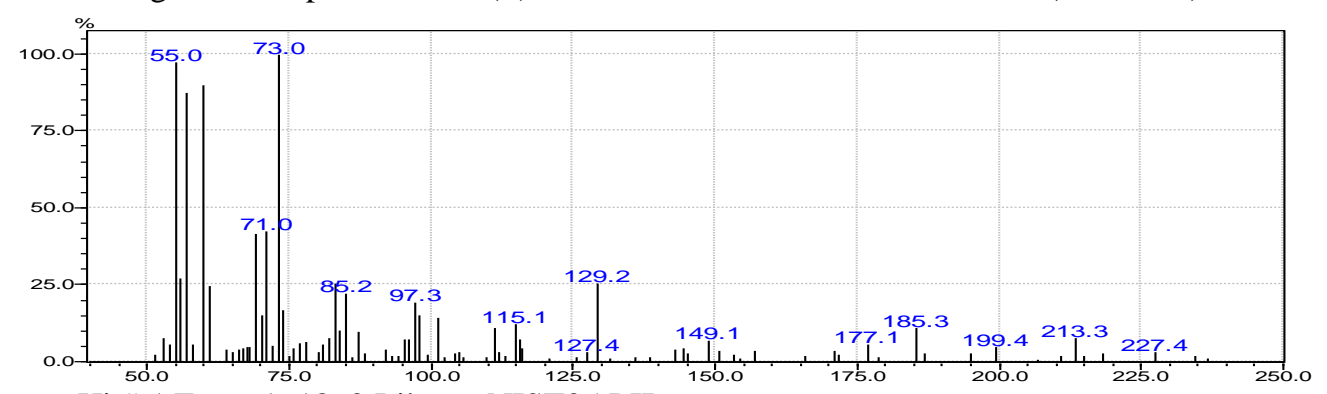

Hit\#:1 Entry:161860 Library:NIST05.LIB

SI:82 Formula:C38H68O8 CAS:28474-90-0 MolWeight:652 RetIndex:4765

Compound Name:1-(+)-Ascorbic acid 2,6-dihexadecanoate

Fig 6. Mass spectrum of 1-(+)-Ascorbic acid 2,6-dihexadecanoate (RT:18.556)

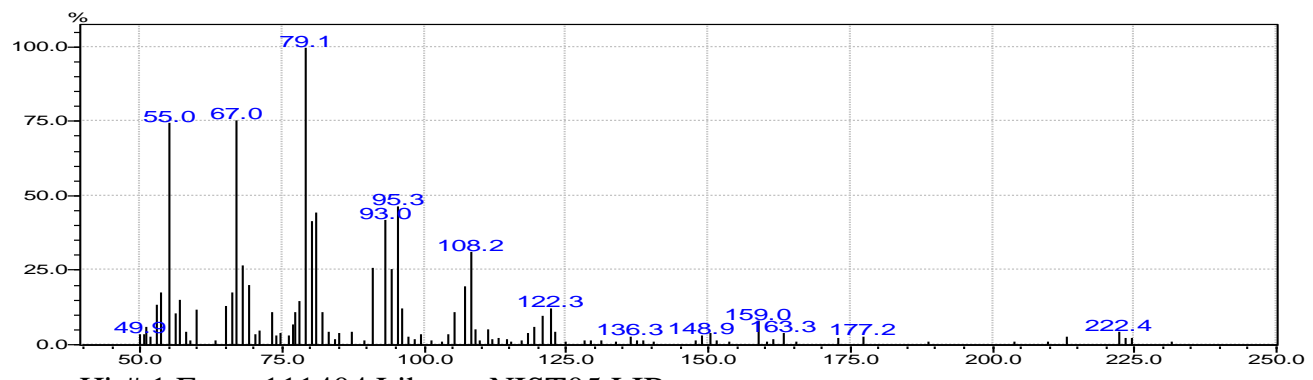

Hit\#:1 Entry:111404 Library:NIST05.LIB

SI:81 Formula:C21H34O2 CAS:59149-1-8 MolWeight:318 RetIndex:2308

Compound Name:Methyl (Z)-5,11,14,17-eicosatetraenoate \$ Methyl (5Z,11Z,14Z,17Z)-

$5,11,14,17$ - icosatetraenoate \# \$

\section{CONCLUSION}

GCMS analysis of the ethanol extract of $P$ daemia reveals the presence of medicinally valued bioactive components like tannins, saponin, terpenoid, alkaloids, flavonoids and steroids. As the medicinal value of similar components in other plant extracts are already proved, no wonder if these components in $P$ daemia may also have equally effective, if not more, therapeutic values. The work is in progress to ascertain its biological activity and brighten the pharmacological profile of it in the arena of traditional medicine.

\section{ACKNOWLEGEMENT}

We would like to thank the BMDLAB SERVICES PVT LTD for their immense help in making GCMS analysis of the plant extract. 


\section{REFERENCES:}

[1] WHO, IUCN, WWF. 1993. Guidelines on the conservation of medicinal plants. Switzerland: IUCN Gland

[2] Yoganarasimhan SN. 2000. Medicinal Plants of India. Vol. 1 Bangalore: Interline Publishing Pvt. Ltd, p. 405. ISBN: 81-7296-03709.

[3] Mittal OP, Tammz C, Reichstein T. 1962. Glycosides and aglycons. CCXXVII. The glycosides of Pergularia extensa. Helv Chim Acta; 45: 907.

[4] Elango V, Ambujavalli L, Amala Basker E, Sulochana N. 1985. Pharmacological and microbiological studies on Pergularia extensa. Fitoterapia; 56 (5): 300-302.

[5] Kakrani HKN, Saluja AK. 1994. Traditional treatment through herbs in Kutch district, Gujarat state, India. Part II. Analgesic, antiinflammatory, antirheumatic, antiarthritic plants. Fitoterapia; 65 (5): 427-430.

[6] De laszlo H, Henshaw PS. 1954. Plant materials used by primitive peoples to affect fertility. Science; 119: 626-631.

[7] Dutta A, Ghosh S. 1947b. Daemia extensa. Indian J Pharmacy; 9: 58-60.

[8] Pushpangadan P, Atal CK. 1984. Ethno-medico-botanical investigations in Kerala I. Some primitive tribals of Western Ghats and their herbal medicine. J Ethnopharmacol; 11 (1): 59-77.

[9] Kokwaro JO. A review of research on plants for fertility regulation in Africa. Proc who symposium on plant-derived products for fertility regulation. 1981. Seoul, Korea. February. p. 8.

[10] Reddy MB, Reddy KR, Reddy MN. 1989. A Survey of plant crude drugs of Anantapur district, Andhra Pradesh, India. Int J Crude Drug Res; 27(3): 145-155.

[11] Kohler I, Jenett Siems K, Kraft C, Siems K, Abbiw D, Bienzle U, Eich E. 2002. Herbal remedies traditionally used against malaria in Ghana: Bioassay-guided fractionation of Microglossa pyridolia (asteraceae). Z Nature Forsch Ser C; 57C (11/12): 1022-1027.

[12] Gill LS, Akinwumi C. 1986. Nigerian folk medicine: Practices and beliefs of the Ondo people. J Ethnopharmacol. 18(3): 259-266.

[13] V.H. Bhaskar and N. Balakrishnan. 2009. Veliparuthi (Pergularia daemia (Forsk.) Chiov.) - As a phytomedicine: A review. International Journal of Pharm Tech Research, Vol.1, No.4, pp 1305-1313.

[14] Dutta A, Ghosh S. 1947a. Chemical examination of Daemia extensa. I. J Amer. 2006. Pharm Ass Sci Ed; 36: $250-252$.

[15] Rastogi RP and Mehrotra BN. Compendium of Indian medicinal plants. Vol2 (1970-1979).New Delhi, India: Central Drug Research, Lucknow and NISCAIR; p. 521.

[16] http://en.wikipedia.org/wiki/Gas_chromatography\%E2\%80\%93mass_spectrometry - Gas chromatography-mass spectrometry from Wikipedia, the free encyclopedia

[17] http://www.gmu.edu/depts/SRIF/tutorial/gcd/gc-ms2.htm)

[18] Ismaila Y. Sudi, Denban M. Ksgbiya1 and Emmanuel K. Muluh1. 2011. Nutritional and phytochemical screening of Senna obtusifolia indigenous to Mubi nigeria, Advances in Applied Science Research. 2(3), 432-437

[19] Mukeshwar Pandey, Mousumi Debnath et al. 2011. Phytomedicine: An ancient approach turning into future potential source of therapeutics, Journal of Pharmacognosy and phytotherapy, 3(1), 113-117

[20] Victor Njoku O. and Chidi Obi. 2009. Phytochemical constituents of some selected medicinal plants, African Journal of Pure and Applied Chemistry, 3(11), 228-233

[21] Alagesaboopathi C. and Sivakumar R. 2011. Antimicrobial properties of various extracts of andrographis neesiana wight-an endemic medicinal species from India, International Journal of Pharmatech research, 3(1), 27-31 